\title{
Combat cancer!
}

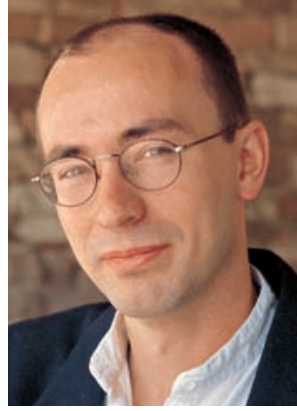

Dr. med. Dieter Schmid, Redaktionsleitung
Kleines Gedankenexperiment: Angenommen, Sie hätten die Möglichkeit, für eine Minute Gott zu spielen und dürften eine Krankheit von der Erde verdammen. Welche würden Sie wählen? Den Herzinfarkt? AIDS? Die Altersdemenz? Viele dürften für den Krebs plädieren - und das zu Recht. Denn laut WHO gebührt diesem Leiden demnächst ganz offiziell der Titel „schlimmste Geisel der Menschheit“. Krebs wird 2010 die Herz-Kreislauf-Erkrankungen an der Spitze der Todesursachenstatistik ablösen. 2008 starben weltweit 7 Millionen Menschen an dieser Krankheit, 2030 werden es bis zu 17 Millionen sein - Gründe dafür sind die zunehmende Fettleibigkeit und der ungebremste Tabakkonsum vieler Menschen.

Für Sie als junger Mediziner bedeutet dies, dass Sie später noch öfter als heutige Kollegen Krebspatienten behandeln werden. Egal, ob als Internist, Gynäkologe, Neurologe oder Urologe - immer wieder werden Sie Menschen erklären müssen, dass sie an dieser Krankheit leiden. Im Artikel „Passende Worte mit SPIKES“ auf S. 32 erklären wir Ihnen einen Weg, wie Sie diese Aufgabe einfühlsam und gewissenhaft erfüllen können. Einer der im Artikel zitierten Ärzte gibt den Tipp, man möge sich bei der Diagnosevermittlung einen Menschen vorstellen, der einem auch persönlich nahesteht. Vielen fällt das leichter, als ihnen lieb ist. Fast jeder hat einen nahen Verwandten, der an Krebs erkrankt ist. Manche haben sogar selbst diese Hölle durchlebt. Unter www.thieme.de/viamedici finden Sie in der Rubrik „Ärztliches Handeln“ den Bericht einer jungen Ärztin, die an Brustkrebs erkrankt ist. Eindrucksvoll beschreibt sie die Zäsur, die diese Diagnose in ihr Leben schneidet. Dieser Artikel ist ein Weckruf für alle, die vor dem Hintergrund ihrer Jugend Gesundheit als eine Selbstverständlichkeit ansehen - und ein Lehrstück darüber, wie eine Aufklärung nicht laufen sollte: Die Autorin bekam den histopathologischen Befund ihres Karzinoms versehentlich per Post zugesandt.

Ob die Zahl der Krebstoten in den kommenden Jahren tatsächlich so dramatisch ansteigen wird wie von der WHO vermutet, hängt auch von den Menschen ab, die in den Laboren dieser Welt nach neuen Therapien suchen. Sie als junger Mediziner haben die Chance, bei dieser Aufgabe mitzuwirken. Ein guter Weg, eine Forscherkarriere zu beginnen, ist, dorthin zu gehen, wo die besten Wissenschaftler dieser Welt arbeiten: Das ist nach wie vor Nordamerika. Im Artikel „Let’s go Harvard“ auf S. 8 geben wir Ihnen Tipps, wie Sie „über den Teich“ an ein Forschungspraktikum kommen und auf was Sie achten sollten. Wer weiß? Vielleicht können Sie durch eine Entdeckung ja mithelfen, zu verhindern, dass die Prognose der WHO eintrifft?

Einen guten Start ins Sommersemester wünscht Ihr

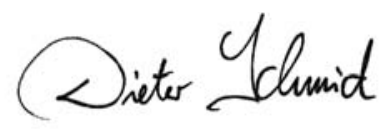

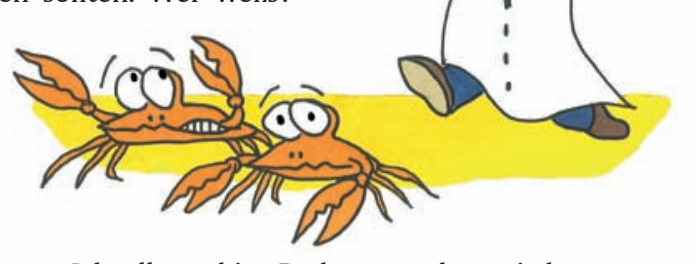

„Schnell weg hier. Da kommt schon wieder dieser verrückte Krebsforscher!“

\section{ONLINE-UMFRAGE}

\section{Religion und Medizin?}

Im Artikel „Klinikstress im Ramadan“ (S. 20) erklären muslimische Studenten, warum es gar nicht so einfach ist, Religion mit Studium und Arztberuf unter einen Hut zu bekommen. Das gilt nicht nur für Moslems - auch Christen und Juden knurrt in der Fastenzeit oder an Jom Kippur der Magen, während sich die anderen das Mensaessen schmecken lassen. Würden Sie Kommilitonen unterstützen, die auch in Uni oder Klinik ihren Glauben praktizieren möchten? Oder würden Sie genervt Contra geben, wenn ein Kollege sich während der Arbeit zum Gebet zurückzieht und Prüfungen oder Nachtdienste aufgrund religiöser Feierlichkeiten verschiebt?

- Sollte in Studium und Klinik Rücksicht auf die religiösen Gepflogenheiten gläubiger Menschen genommen werden?

Stimmen Sie ab und sagen Sie Ihre Meinung unter: www.thieme.de/viamedici/aktuelles/aktion/ miniumfrage2_09.html
- Ergebnis der Umfrage in Via medici 1.09: Wir fragten, ob der Verdienst als Arzt für Sie ein zentraler Grund dafür ist, dass Sie Medizin studieren. Zwar wiesen das 76 Prozent der Teilnehmer weit von sich. Doch immerhin 20 Prozent motiviert tatsächlich primär ihr künftiges Gehalt. „Für die Verantwortung, die ich später trage, will ich auch entlohnt werden!“, meint ein Student. Ein Kommilitone kontert: „Ich studiere Medizin aus Liebe zum Fach und zu den Menschen. Um reich zu werden, müsste ich ein anderes Fach lernen." Alle Kommentare unter: .../aktuelles/aktion/miniumfrage1_09.html 